\title{
Experimental evidence for the role of bioturbation by the marine nematode Diplolaimella dievengatensis in stimulating the mineralization of Spartina anglica detritus
}

\author{
R. Alkemade*, A. Wielemaker, S. A. de Jong**, A. J. J. Sandee \\ Netherlands Institute of Ecology - Centre for Estuarine and Coastal Ecology, Vierstraat 28, 4401 EA Yerseke, The Netherlands
}

\begin{abstract}
The effect of the bacterivorous nematode Diplolaimella dievengatensis on the diffusion of oxygen into sediment and the $\mathrm{CO}_{2}$ production of Spartina anglica detritus was examined in a laboratory experiment. Diffusion coefficients were calculated from measurements of both $\mathrm{O}_{2}$ consumption, using gas chromatography, and $\mathrm{O}_{2}$ micro-gradients, using micro-electrodes. After a transient state of about $10 \mathrm{~d}$ the diffusion and consumption of oxygen stabilized and approached steady state. In treatments with nematodes $\mathrm{O}_{2}$ consumption and $\mathrm{CO}_{2}$ production were $74 \%$ higher than in controls. In treatments with nematodes the apparent diffusion coefficient of oxygen was 40 to $70 \%$ higher than the molecular diffusion coefficient due to nematode activity. Since the increases of $\mathrm{CO}_{2}$ production and of the diffusion of oxygen in the presence of nematodes were of the same magnitude, we conclude that the enhanced turnover time of Spartina detritus was largely dependent on the bioturbation activity of the nematodes.
\end{abstract}

\section{INTRODUCTION}

Bacterivorous nematodes of the family Monhysteridae accelerate decomposition processes in marine sediments. Diplolaimella chitwoodi increased the detrital carbon mineralization of Gracilaria and Spartina detritus (Findlay \& Tenore 1982). In the presence of Monhystera disjuncta increased weight losses of seaweed detritus were found by Rieper-Kirchner (1989). In a previous study we found an increased mineralization of organic carbon and increased weight losses of Spartina anglica leaves in the presence of Diplolaimelloides bruciei (Alkemade et al. 1992).

The mechanism by which nematodes accelerate decomposition processes is still unknown. Three possible

\footnotetext{
Present addresses:

- National Institute for Public Health and Environmental Protection, Laboratory LBG, PO Box 1,3720 BA Bilthoven The Netherlands

-North Sea Directorate, PO Box 5807, 2280 HV Rijswijk, The Netherlands
}

mechanisms have been suggested. Firstly, removal of senescent bacterial cells by grazers might stimulate bacterial growth by keeping the bacterial population active (Abrams \& Mitchell 1980). Secondly, Riemann \& Schrage (1978) suggested that mucus produced by nematodes provides a rich food source for bacteria resulting in increased bacterial growth. Bioturbation has been suggested as a third mechanism by which nematodes stimulate bacterial activity (Abrams \& Mitchell 1980, Herman \& Vranken 1988). Bioturbation is the process resulting from the mixing activities of benthic organisms (Berner 1980). The mixing activities enhance the diffusion of oxygen (Hofman et al. 1991) and would thereby stimulate aerobic bacterial activity.

In this study we investigated the effects of the bacterivorous nematode Diplolaimella dievengatensis on the diffusion of $\mathrm{O}_{2}$ and the mineralization of organic carbon in an artificial sediment enriched with Spartina anglica detritus. $D$. dievengatensis is frequently found in sediments of salt marshes with $S$. anglica vegetation in the southwestern part of the Netherlands. Bioturbation was estimated from the diffusion coefficient of 
oxygen. An enhanced diffusion coefficient relative to molecular diffusion is a measure for bioturbation (Berner 1980). The diffusion coefficient was determined by combined measurements of $\mathrm{O}_{2}$ consumption rates and $\mathrm{O}_{2}$ micro-gradients. Mineralization of organic carbon (measured as $\mathrm{CO}_{2}$ production) was determined simultaneously.

\section{MATERIAL AND METHODS}

Nematode culture. Specimens of Diplolaimella dievengatensis were extracted from the sediment as described by Vranken et al. (1981). Culture dishes containing bacto-agar, Vlasblom-medium and $\mathrm{Na}_{2} \mathrm{SiO}_{3} \cdot 9 \mathrm{H}_{2} \mathrm{O}$ (Vranken et al. 1988) were inoculated with 10 to 20 adult specimens of $D$. dievengatensis and a droplet of filtered $(1.2 \mu \mathrm{m})$ seawater. Before inoculating the nematodes onto the culture dishes an extra transfer step was performed in order to avoid contamination by ciliates and other protozoa (Alkemade et al. 1992).

Experimental design. Green Spartina anglica leaves were collected on the Stroodorpepolder salt marsh in the Oosterschelde, a tidal inlet of the southern North Sea. Leaves were dried at $50^{\circ} \mathrm{C}$ for $24 \mathrm{~h}$, ground and sieved. Sand was cleaned with $\mathrm{HCl}$ and $\mathrm{H}_{2} \mathrm{O}_{2}$ in order to remove organic matter, and subsequently sieved Leaf particles and sand grains which passed a $90 \mu \mathrm{m}$ mesh sieve and that were retained on a $45 \mu \mathrm{m}$ mesh sieve were used in the experiment. The leaf particles were mixed with sand and 8 petri dishes $(\varnothing 3.5 \mathrm{~cm})$ were filled with a $6 \mathrm{~mm}$ thick layer of this mixture. The initial organic carbon content of the mixture was $0.36 \%$, a value found in many natural sediments. Autoclaved seawater from the Oosterschelde (salinity $26 \%$ ) was added. A very thin water film was present on the sediment, indicating water-saturated conditions.

The dishes were inoculated with a natural bacterial inoculum, obtained by rinsing decaying Spartina anglica leaves in autoclaved seawater and subsequently filtering the water over a $1.2 \mu \mathrm{m}$ micropore filter. Each dish received $100 \mu \mathrm{l}$ of the inoculum. Finally, 50 to 100 nematodes were added to 4 dishes: the others served as control treatments. The dishes were placed in the dark in an incubator at $20^{\circ} \mathrm{C}$ in water-saturated air

After $22 \mathrm{~d}$, at the end of the experiment, nematodes were fixed in warm formalin, extracted from the sediment and counted under a dissecting microscope. The nematode biomass was estimated by the volumetric method of Andrassy (Feller \& Warwick 1988).

$\mathrm{CO}_{2}$ production and $\mathrm{O}_{2}$ consumption measurements. $\mathrm{CO}_{2}$ production and $\mathrm{O}_{2}$ consumption were measured regularly during the course of the experiment using gas chromatography (Mitchell 1973, Abrams \& Mitchell
1980). The petri dishes were incubated at $20^{\circ} \mathrm{C}$, in the dark, in an air-tight chamber $(20 \mathrm{ml})$ for 1 to $4 \mathrm{~h}$ (dependent on the $\mathrm{CO}_{2}$ production in the dish). $\mathrm{CO}_{2}$ and $\mathrm{O}_{2}$ concentrations in the incubation chambers were measured before and after incubation by injecting air samples on a Packard 427 gas chromatograph (details in Alkemade et al. 1992). The $\mathrm{CO}_{2}$ and $\mathrm{O}_{2}$ flux are expressed as the $\mathrm{CO}_{2}$ production and $\mathrm{O}_{2}$ consumption per $\mathrm{m}^{2}$ per hour. Cumulative $\mathrm{CO}_{2}$ production and $\mathrm{O}_{2}$ consumption were calculated from $\mathrm{CO}_{2}$ and $\mathrm{O}_{2}$ fluxes measured on subsequent sampling days by linear interpolation and subsequent integration

Oxygen micro-profiles were measured with oxygen micro-electrodes as described by Revsbech \& Jørgensen (1983) and de Jong et al. (unpubl.). The oxygen micro-profile is graphically represented by plotting the oxygen concentration, measured at one sampling time, against depth. The oxygen micro-gradient is referred to as the slope of the micro-profile calculated by linear regression. The micro-electrodes were constructed at our institute. The theory of using micro-electrodes in mineralization processes is described in Hofman et al. (1991).

Calculation of the apparent sediment diffusion coefficient. The oxygen flux into the sediment can be described by Fick's first law of diffusion (Berner 1980):

$$
J_{\mathrm{O}_{2}}=-\phi D_{\mathrm{a}}\left(\frac{\mathrm{dO}}{\mathrm{d} x}\right)_{x=0}
$$

where $J_{\mathrm{O}_{2}}=$ flux of oxygen $\left(\mathrm{mmol} \mathrm{O}_{2} \mathrm{~m}^{-2} \mathrm{~h}^{-1}\right) ; \phi=$ mean porosity for oxic sediment layer, defined as the volume of water relative to the volume of total sediment; $D_{\mathrm{a}}=$ apparent diffusion coefficient $\left(\mathrm{m}^{2} \mathrm{~h}^{-1}\right)$ and $\mathrm{dO}_{2} / \mathrm{d} x=$ oxygen micro-gradient over depth interval $x$ ( $\mathrm{mmol} \mathrm{O} \mathrm{m}^{-4}$ ).

The apparent diffusion coefficient is calculated by rewriting Eq. 1 in the form:

$$
D_{\mathrm{a}}=-\frac{J_{\mathrm{O}_{2}}}{\phi\left(\frac{\mathrm{dO}}{\mathrm{d} x}\right)_{x=0}}
$$

The flux of oxygen $\left(J_{\mathrm{O}_{2}}\right)$ was calculated from the rate of change of oxygen concentration measured in incubation chambers by gas chromatography. Exact values of $D_{\mathrm{a}}$ could not be calculated, because the micro-gradient depends on the depth interval from which it is derived This depth dependence may be due to porosity changes with depth (e.g. Archer et al. 1989, Booij et al. 1991). In order to determine a range for the diffusion coefficient, we estimated the oxygen micro-gradient using 4 different depths intervals. The series of oxygen microgradients calculated per profile together with the corresponding independent estimates of the oxygen fluxes were used for calculation of the apparent diffusion coefficients. Estimates, obtained by linear interpolation, 
of the oxygen fluxes were used, because fluxes and micro-profiles could not be measured at the same time. In the absence of bioturbation the apparent diffusion coefficient equals the bulk sediment diffusion coefficient $\left(D_{\mathrm{s}}\right)$; in the presence of bioturbation the apparent diffusion coefficient is higher.

The bulk sediment diffusion coefficient is calculated by correcting the free solution diffusion coefficient $\left(D_{0}\right)$ for mean porosity of the sediment (Broecker \& Peng 1974, Hofman et al. 1991). Since we found a mean porosity of about 0.50 the bulk sediment diffusion coefficient is calculated from: $D_{\mathrm{s}}=D_{0} \phi$, according to Ullman \& Aller (1982).

Statistical analysis. Measurements of $\mathrm{O}_{2}$ consumption, $\mathrm{CO}_{2}$ production and $\mathrm{O}_{2}$ micro-gradients were initially carried out daily in order to detect the beginning of a stabilized situation. In a stabilized situation no major changes occur between succesive sampling days. The diffusion and the consumption of oxygen then approach a steady state. Time lapses between sampling days were longer in the steady state period. Multivariate analysis of variance with a repeated measures design was used to evaluate the differences found between treatments with and without nematodes during the steady state period. SYSTAT (Wilkinson 1990) was used for statistical calculations.

\section{RESULTS}

\section{$\mathrm{CO}_{2}$ production and $\mathrm{O}_{2}$ consumption}

At the beginning of the experiment the $\mathrm{O}_{2}$ consumption, $\mathrm{CO}_{2}$ production and $\mathrm{O}_{2}$ micro-gradients changed rapidly from day to day (Figs. 1 \& 3). During this 'transient state' the $\mathrm{CO}_{2}$ production per hour was high and decreased gradually to a more or less stable level after about $5 \mathrm{~d}$. No major changes of gas fluxes occurred after the first $5 \mathrm{~d}$, but the micro-gradients and the maximal penetration depth of oxygen remained variable until after about $10 \mathrm{~d}$ (see below). The period from $10 \mathrm{~d}$ onwards to the end of the experiment is considered to represent a steady state.

$\mathrm{O}_{2}$ consumption per hour was an almost identical reflection of the $\mathrm{CO}_{2}$ production pattern (Fig. 1). The respiratory quotient $\left(=-\mathrm{dCO}_{2} / \mathrm{dO}_{2}\right)$ ranged from 0.77 to 0.84 ( 0.80 on average), which indicates that carbon was accumulated in bacterial and nematode biomass during the course of the experiment. In the presence of nematodes more $\mathrm{CO}_{2}$ was produced and more $\mathrm{O}_{2}$ was consumed per hour during the steady state. This resulted in a $26 \%$ higher cumulative $\mathrm{CO}_{2}$ production in treatments with nematodes at the end of the experiment (Fig. 2). The cumulative $\mathrm{CO}_{2}$ production was significantly higher $(p<0.05$, Table 1$)$ during the steady state period.

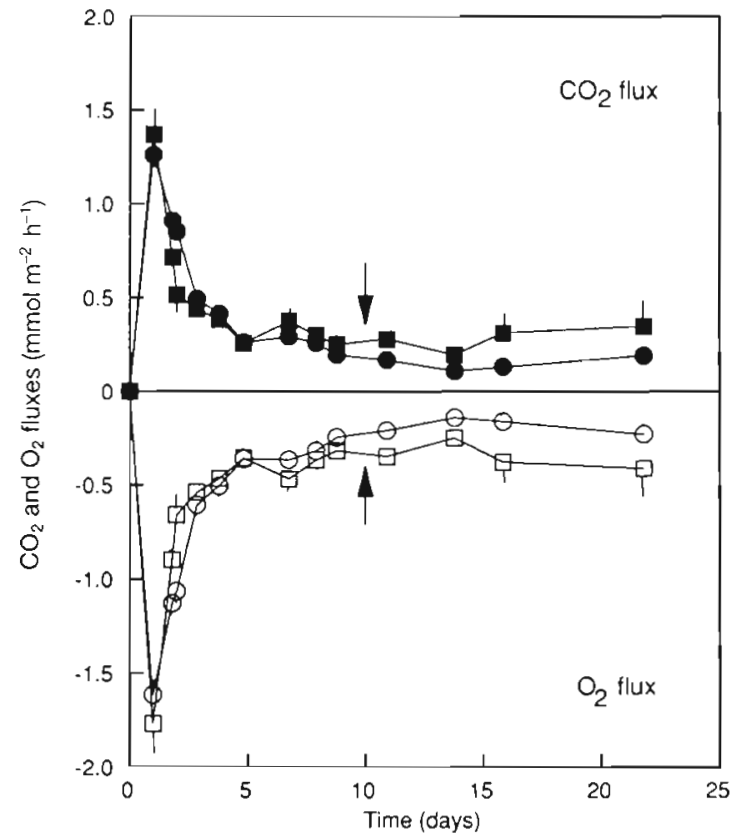

Fig. 1. $\mathrm{CO}_{2}$ and $\mathrm{O}_{2}$ fluxes in the sediment during the course of the experiment. (ロ) $\mathrm{CO}_{2}$ flux with nematodes; (-) $\mathrm{CO}_{2}$ flux without nematodes, ( $\square$ ) $\mathrm{O}_{2}$ flux with nematodes; (O) $\mathrm{O}_{2}$ flux without nematodes. All points are mean values of 4 replicates. Vertical bars indicate 1 standard error. Arrows indicate the beginning of the steady state period

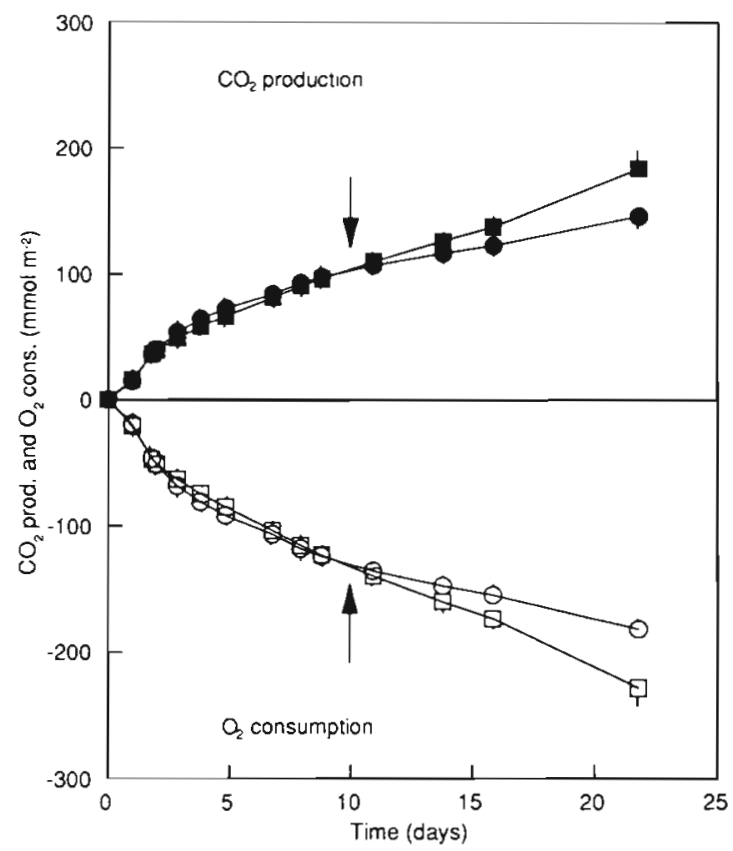

Fig. 2. Cumulative $\mathrm{CO}_{2}$ production and $\mathrm{O}_{2}$ consumption in the sediment during the course of the experiment. (四 $\mathrm{CO}_{2}$ production with nematodes; (-) $\mathrm{CO}_{2}$ production without nematodes; ( $\square$ ) $\mathrm{O}_{2}$ consumption with nematodes; $(O) \mathrm{O}_{2}$ consumption without nematodes. All points are mean values of 4 replicates. Vertical bars indicate 1 standard error. Arrows indicate the beginning of the steady state period 
Table 1 Multivariate repeated measures analysis: univariate test statistics of (A) cumulative $\mathrm{CO}_{2}$ production, (B) apparent oxygen diffusion coefficients calculated from the depth interval $0.05-1.0 \mathrm{~mm}$ and $(\mathrm{C})$ oxygen penetration depth

\begin{tabular}{|c|c|c|c|c|c|}
\hline Variable & SS & $\mathrm{df}$ & MS & $F$ & $\mathrm{p}$ \\
\hline \multicolumn{6}{|l|}{ (A) $\mathrm{CO}_{2}$ production } \\
\hline \multicolumn{6}{|l|}{ Between subjects } \\
\hline Nematodes & 2661 & 1 & 2661 & 7.36 & 0.035 \\
\hline Error & 2169 & 6 & 362 & & \\
\hline \multicolumn{6}{|l|}{ Within subjects } \\
\hline Time & 20380 & 2 & 10190 & 39.41 & 0.001 \\
\hline Time $\times$ Nematodes & 2040 & 2 & 1020 & 3.95 & 0.048 \\
\hline Error & 3103 & 12 & 259 & & \\
\hline \multicolumn{6}{|c|}{ (B) Apparent oxygen diffusion coefficients } \\
\hline \multicolumn{6}{|l|}{ Between subjects } \\
\hline Nematodes & 140 & 1 & 140 & 11.00 & 0.016 \\
\hline Error & 77 & 6 & 13 & & \\
\hline \multicolumn{6}{|l|}{ Within subjects } \\
\hline Time & 3.07 & 2 & 1.53 & 0.31 & ns \\
\hline Time $\times$ Nematodes & 19.91 & 2 & 9.95 & 2.01 & ns \\
\hline Error & 59.29 & 12 & 4.94 & & \\
\hline \multicolumn{6}{|c|}{ (C) Oxygen penetration depth } \\
\hline \multicolumn{6}{|c|}{ Between subjects } \\
\hline Nematodes & 0.74 & 1 & 0.74 & 8.83 & 0.025 \\
\hline Error & 0.50 & 6 & 0.08 & & \\
\hline \multicolumn{6}{|l|}{ Within subjects } \\
\hline Time & 0.11 & 2 & 0.06 & 1.79 & ns \\
\hline Time $\times$ Nematodes & 0.02 & 2 & 0.01 & 0.36 & ns \\
\hline Error & 0.38 & 12 & 0.03 & & \\
\hline
\end{tabular}

\section{Oxygen micro-profiles}

The micro-profiles in sediments measured on Day 3 , in the transient state period of the experiment, and on Day 11, in the steady state period, are shown in Fig. 3. Profiles with (Fig. 3A) and without nematodes (Fig. 3B) are shown. During the transient state, the oxygen micro-profiles in the sediment were steep and changed from day to day, corresponding with high $\mathrm{O}_{2}$-fluxes at the beginning of the experiment (see Fig. 1). After $10 \mathrm{~d}$ micro-profiles were, in general, less steep and no major changes occurred, corresponding with the stabilization of the $\mathrm{O}_{2}$ fluxes. During the course of the experiment the oxygen was only present in the upper few millimeters. In this upper layer the bacteria apparently were active and consumed all oxygen diffusing into the sediment. In deeper layers no oxygen was present and therefore no aerobic mineralization took place. At the sediment surface the $\mathrm{O}_{2}$ concentration was about $300 \mu \mathrm{M}$ in all profiles, corresponding with $\mathrm{O}_{2}$ saturation. The oxygen concentration appeared to decrease non-linearly with depth. In the upper $0.2 \mathrm{~mm}$ the $\mathrm{O}_{2}$ concentration declined very quickly in all profiles, followed by a gradually lesser steep decline. From Day 10 onwards no major changes of micro- profiles were observed, indicating the establishment of steady state. The oxygen diffusion and the oxygen consumption apparently were in balance. At comparable depths, the $\mathrm{O}_{2}$ concentrations were higher in sediments without nematodes than in sediments with nematodes. Oxygen penetration stabilized at lower depths in the absence of nematodes ( $p<0.05$, Table 1) and disappeared, on average, below $1.6 \mathrm{~mm}$ in sediments with nematodes, and below $2 \mathrm{~mm}$ in sediments without nematodes (Fig. 4).

\section{Apparent diffusion coefficients}

The apparent diffusion coefficients were calculated for the steady state situation only. For each micro-profile, micro-gradients were calculated over 4 depth intervals: $0-0.15 \mathrm{~mm}, 0-0.4 \mathrm{~mm}$, 0.05-1.0 $\mathrm{mm}$ and from 0.05 downwards to the maximum depth of the oxic zone.

Table 2 shows the apparent diffusion coefficients calculated for different depth intervals. The apparent diffusion coefficient depended largely on the depth interval from which it was derived. For each depth interval, however, the values of the diffusion coefficient in treatments with nematodes was higher than in treatments without nematodes. The apparent diffusion coefficients in the control treatments calculated from the depth intervals from $0.05 \mathrm{~mm}$ to $1.0 \mathrm{~mm}$ and from $0.05 \mathrm{~mm}$ to maximal depth were close to the bulk sediment diffusion coefficient, which was obtained by multiplying the porosity $(\phi \approx 0.5)$ by the free solution diffusion coefficient $\left(D_{0}=7.4 \times 10^{-6} \mathrm{~m}^{2} \mathrm{~h}^{-1}\right.$ at $20^{\circ} \mathrm{C}$; Broecker \& Peng 1974) and are therefore considered to be the best estimates. Analysis of variance was carried out on the apparent diffusion coefficients calculated for the 0.05 to $1.0 \mathrm{~mm}$ depth interval. The diffusion coefficients in treatments with nematodes were significantly higher than in control treatments $(p<0.05$, Table 1$)$.

\section{Nematodes}

The number of nematodes increased from between 50 and 100 individuals per dish at the beginning of the experiment to a mean number of $1010(\mathrm{SD}=196)$ at the end of the experiment. These 1010 specimens of Diplolaimella dievengatensis represent an estimated biomass of $0.16 \mathrm{mg}$ wet weight. 
Oxygen concentration (mM)
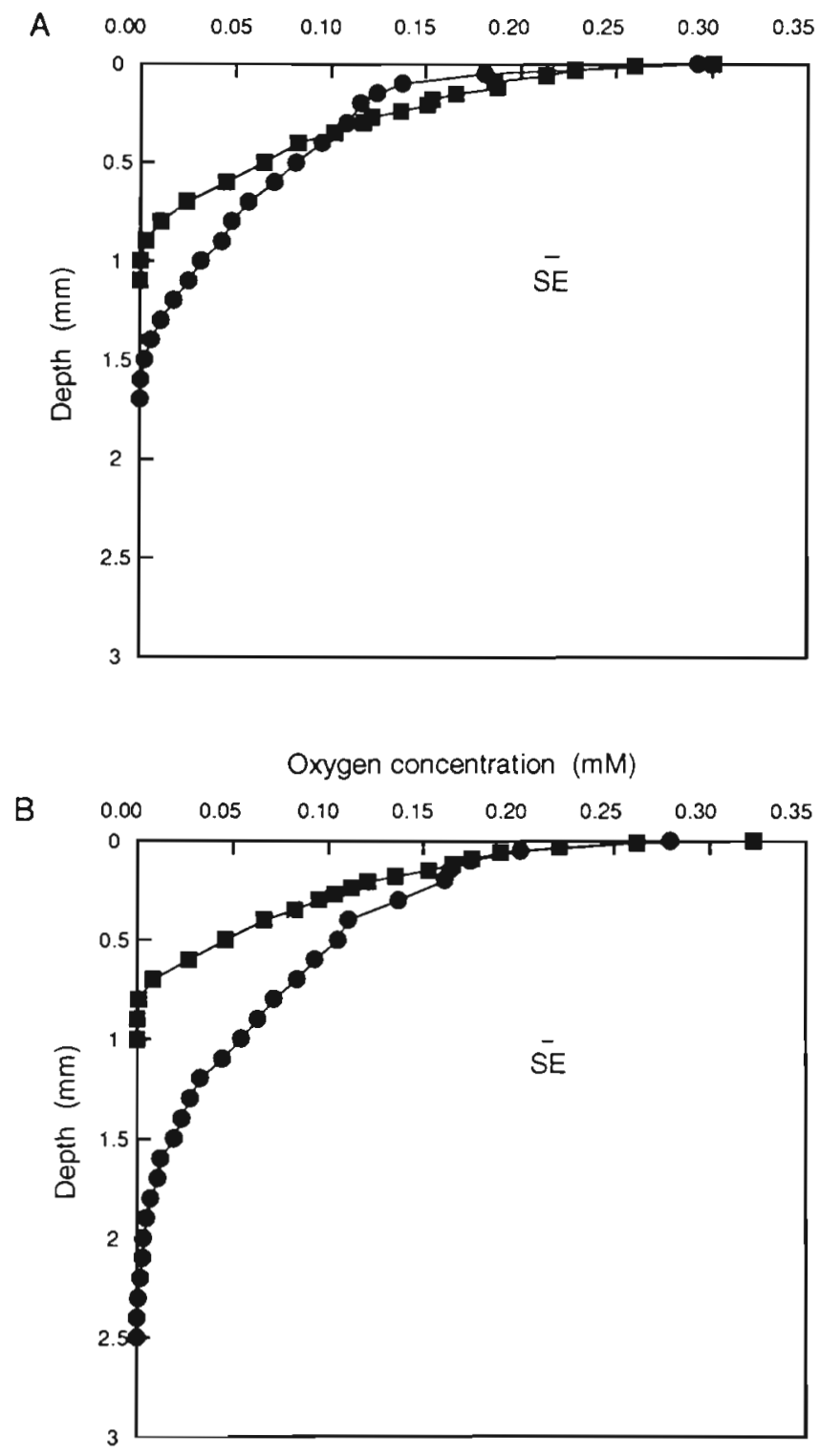

Fig. 3. Oxygen microprofiles measured on Day $3(\square)$, in the first period of the experiment, and on Day $11(\bullet)$, in the steady state situation. (A) In presence of nematodes; (B) in absence of nematodes. All points are mean values of 8 measurements. Horizontal bars, denoted by SE, indicate the mean standard error for all points

\section{DISCUSSION}

During the transient state the $\mathrm{CO}_{2}$ production and $\mathrm{O}_{2}$ consumption rapidly increased and, after a few days, slowly decreased. This pattern was observed by several authors after incubating micro-organisms in a microcosm (Abrams \& Mitchell 1980, Anderson et al. 1981, Findlay \& Tenore 1982). In the beginning of the

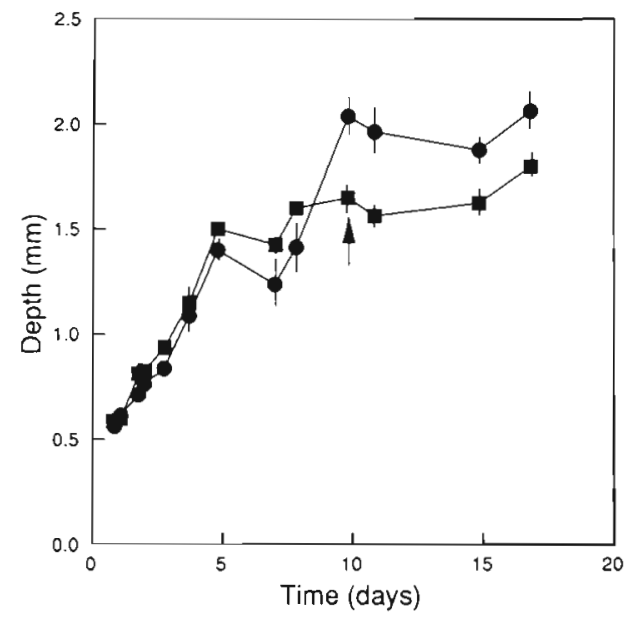

Fig. 4. Penetration depth of oxygen into the sediment during the course of the experiment. (ם) Sediment with nematodes;

(-) sediment without nematodes. All points are mean values of 8 measurements. Vertical bars indicate 1 standard error.

Arrow indicates the beginning of the steady state period

experiment, the high bacterial activity is probably a result of the large quantity of dissolved organic matter (DOM) released from the detritus after wetting the sediment. The DOM forms an immediately available, rich food source for the bacteria and consequently bacterial activity rapidly increases, resulting in high $\mathrm{CO}_{2}$ production and $\mathrm{O}_{2}$ consumption. During the transient state the oxygen micro-gradients were very steep and oxygen was depleted to within a few tenths of a millimeter from the sediment surface.

The initial quantity of easy assimilable substrate presumably was exhausted rapidly and, as a result, bacterial activity declined and stabilized at a much lower level. After about $10 \mathrm{~d}$ a steady state was established. During the steady state pronounced differences between the treatments with nematodes and without nematodes were observed. In the presence of Diplolaimella dievengatensis $74 \%$ more $\mathrm{CO}_{2}$ was produced per hour and $74 \%$ more $\mathrm{O}_{2}$ was consumed per hour, resulting in a $26 \%$ higher mineralization of organic carbon over the total period of the experiment. The diffusion coefficient of oxygen was 40 to $70 \%$ higher in the presence of nematodes (Table 2), but the maximum penetration depth was lower (Fig. 4).

The $\mathrm{O}_{2}$ consumption and $\mathrm{CO}_{2}$ production presumably depended almost completely on the bacterial activity, since the total respiration of the nematodes was only limited. The weight specific respiration of nematodes is $0.029 \mathrm{nmol} \mathrm{O}_{2} \mathrm{~h}^{-1} \mu \mathrm{g}^{-1}$ wet wt (Heip et al. 1985). The total wet weight of the nematodes at the end of the experiment was $0.16 \mathrm{mg}$ per dish, on average. So, the estimated respiration of the nematodes in the dishes was $4.6 \mu \mathrm{mol} \mathrm{O} \mathrm{O}^{-1} \mathrm{~m}^{-2}$, which represents only $2 \%$ of the total respiration on the last sampling 
Table 2. Apparent diffusion coefficient $\left(\times 10^{-6} \mathrm{~m}^{2} \mathrm{~h}^{-1}\right)$ in presence and absence of nematodes calculated for 4 different depth intervals. Values are means over the whole steady state $(n=14)$. (Bulk sediment diffusion coefficient D. $=3.6 \times 10^{-6} \mathrm{~m}^{2} \mathrm{~h}^{-1}$ )

\begin{tabular}{|lcc|}
\hline Depth interval & Without nematodes & With nematodes \\
\hline 0.0 to $0.15 \mathrm{~mm}$ & $0.65 \pm 0.19$ & $0.91 \pm 0.44$ \\
0.0 to $0.40 \mathrm{~mm}$ & $1.42 \pm 0.40$ & $2.13 \pm 0.80$ \\
0.05 to $1.0 \mathrm{~mm}$ & $3.17 \pm 0.93$ & $5.40 \pm 1.60$ \\
0.05 to max. depth & $4.56 \pm 1.65$ & $6.98 \pm 1.93$ \\
\hline
\end{tabular}

day. The increased $\mathrm{O}_{2}$ consumption in the presence of nematodes therefore must be the result of the influence of the nematodes on the bacterial population. Effects of nematodes were only detectable during the steady state period. Although the nematode population must have grown during the steady state, they apparently did nol affect the steady state as such. Under the conditions of the experiment, the nematodes only changed the level at which the steady state established.

Increased apparent diffusion coefficients are a result of bioturbation (Berner 1980). The mixing activity of the nematodes thus must have been responsible for the increased diffusion coefficients. To date, only qualitative studies on bioturbation by nematodes have been published (Cullen 1973, Nehring et al. 1990). Our results provide for the first time quantitative data on bioturbation by nematodes. Apart from mixing of the sediment caused by movements of the nematodes, structures built by nematodes may also enhance diffusion. Some nematode species form a closely spaced network of thread-like intergranular burrows within the surface layer of the sediment (Cullen 1973). The nematode Ptycholaimellus sp. builds membranous tubes from detritus with the aid of mucus (Nehring et al. 1990). Undoubtedly, small-scale burrow systems will promote the diffusion of oxygen but the quantitative contribution to oxygen diffusion is unclear. The mechanism by which Diplolaimella dievengatensis increased bioturbation in our study remains to be investigated.

In natural sediments, comparable to the sediment we used, the apparent diffusion coefficients were 1.4 to 18.8 times higher than the bulk sediment diffusion coefficient (Hofman et al. 1991). The lower values were found in sediments with a low density of macrofauna, unknown densities of meiofauna, and low contents of organic matter. We found that in the presence of nematodes alone apparent diffusion coefficients were between 1.4 and 1.7 times higher than in sediments without nematodes, where only molecular diffusion occurred. Nematode densities were approximately 1000 individuals per $10 \mathrm{~cm}^{2}$, i.e. similar to densities normally found in marine sediments (Heip et al. 1985). We therefore consider it likely that nematodes will substantially increase bioturbation under field conditions

In the presence of Diplolaimella dievengatensis higher mineralization of organic carbon was observed, This result is in agreement with the findings of Findlay \& Tenore (1982), Rieper-Kirchner (1989) and our earlier findings (Alkemade et al. 1992). The enhanced mineralization in the presence of nematodes may have several possible causes: e.g. grazing of the bacterial population by nematodes may stimulate bacterial activity and therewith the mineralization of detritus (Abrams \& Mitchell 1980). A second possiblity is that the production of mucoid substances by nematodes provides a rich additional food source to the bacteria, stimulating their activity (Riemann \& Schrage 1978). Finally nematodes may stimulate aerobic bacterial activity by the enhanced diffusion of $\mathrm{O}_{2}$, either by the movement of pore water and particles or by a burrow system built by nematodes (Abrams \& Mitchell 1980, Nehring et al. 1990).

Herman \& Vranken (1988) calculated that the bacterivorous nematode Monhystera disjuncta had grazing rates of only a few percent per day and therefore was not able to remove senescent cells quickly enough to stimulate bacterial growth. They hypothesized that bioturbation is more important than grazing in stimulating bacterial activity. We cannot assess the exact importance of grazing in our experimental system nor can we exclude the possibility that the presence of mucus to some extent increases the bacterial activity. However, increased bacterial activity by grazing or by the production of mucus will result in higher $\mathrm{O}_{2}$ consumption, but not in higher diffusion of $\mathrm{O}_{2}$. The higher $\mathrm{O}_{2}$ diffusion resulted from the bioturbation due to the nematodes. The most convincing argument that the enhanced mineralization of organic carbon in the presence of Diplomaimella dievengatensis probably is primarily the consequence of bioturbation is our finding that the increased diffusion on the one hand and the increased oxygen consumption and mineralization of organic carbon on the other hand were of similar magnitude. Grazing and the production of mucus may only have a small additional effect.

Acknowledgements. We thank Dr M. A. Hemminga, Dr P. Hofman, Dr J. Middelburg and Prof. Dr Ir A. F. van der Wal for their critical reading of the manuscript and fruitful discussions and 3 anonymous referees whose comments helped us considerably in improving the text. We thank J. Nieuwenhuize for professional help with the gas chromatography measurements. Communication no. 615 of the Netherlands Institute of Ecology - Centre for Estuarine and Coastal Ecology. 


\section{LITERATURE CITED}

Abrams, B. I., Mitchell, M. J. (1980). Role of nematodebacterial interactions in heterotrophic systems with emphasis on sewage sludge decomposition. Oikos 35: $404-410$

Alkemade, R., Wielemaker, A., Hemminga, M. A. (1992) Stimulation of decomposition of Spartina anglica leaves by the bacterivorous marine nematode Diplolaimelloides bruciei (Monhysteridae). J. exp. mar. Biol. Ecol. 159: $267-278$

Anderson, R. V., Coleman, D. C., Cole, C. V., Elliott, E. T. (1981). Effect of the nematodes Acrobeloides sp. and Mesodiplogaster theritieri on substrate utilization and nitrogen and phosphorus mineralization in soils. Ecology 62: 549-555

Archer, D., Emerson, S., Reimers, C. (1989). Dissolution of calcite in deep-sea sediments: $\mathrm{pH}$ and $\mathrm{O}_{2}$ micro electrode results. Geochim. Cosmochim. Acta 53: 2831-2845

Berner, R. A. (1980). Early diagenesis, a theoretical approach Princeton University Press, Princeton, NJ

Booij, K., Helder, W., Sundby, B. (1991). Rapid redistribution of oxygen in a sandy sediment induced by changes in flow velocity of the overlying water. Neth. J. Sea Res. 28: $149-165$

Broecker, W. S., Peng, T. H. (1974). Gas exchange rate between sea and air. Tellus 26: 21-35

Cullen, D. J. (1973). Bioturbation of superficial marine sediments by interstitial meiobenthos. Nature 242: 323-324

Feller, R. J., Warwick, R. M. (1988). Energetics. In: Higgins, R. P., Thiel, H. (eds.) Introduction to the study of meiofauna. Smithsonian Institute Press, Washington, DC, p. 181-196

Findlay, S. E. G., Tenore, K. R. (1982). Effect of a free-living marine nematode (Diplolaimella chitwoodi) on detrital carbon mineralization. Mar. Ecol. Prog. Ser. 8: 161-166

Heip, C., Vincx, M., Vranken, G. (1985). The ecology of marine nematodes. Oceanogr. mar. Biol. Ann. Rev. 23: $399-489$

Herman, P. M. J., Vranken, G. (1988). Studies of the lifehistory and energetics of marine and brackish-water

This article was submitted to the editor nematodes II. Production, respiration and food uptake by Monhystera disjuncta. Oecologia 77: 457-463

Hofman, P. A. G., de Jong, S. A., Wagenvoort, E. J., Sandee, A. J. J. (1991). Apparent sediment diffusion coefficients for oxygen consumption rates measured with microelectrodes and bell jars: application to oxygen budgets in estuarine intertidal sediments (Oosterschelde, SW Netherlands). Mar. Ecol. Prog. Ser. 69: 261-272

Mitchell, M. J. (1973). An improved method for microrespirometry using gas chromatography. Soil Biol. Biochem. 5: 271-274

Nehring, S., Jensen, P., Lorenzen, S. (1990). Tube-dwelling nematodes: tube construction and possible ecological effects on sediment-water interfaces. Mar. Ecol. Prog. Ser. 64: $123-128$

Revsbech, N. P., Jørgensen, B. B. (1983). Photosynthesis of benthic microflora measured with high spatial resolution by the oxygen microprofile method: capabilities and limitations of the method. Limnol. Oceanogr. 28: 749-756

Riemann, F., Schrage, M. (1978). The mucus-trap hypothesis on feeding of aquatic nematodes and implications for biodegradation and sediment texture. Oecologia 34: 75-88

Rieper-Kirchner, M. (1989). Microbial degradation of North Sea macroalgae: field and laboratory studies. Botanica mar. 32: $241-252$

Ullman, W. J., Aller, R. C. (1982). Diffusion coefficients in nearshore marine sediments. Limnol. Oceanogr. 27. $552-556$

Vranken, G., Thielemans, L. K., Heip, C., Vandycke, M. (1981). Aspects of the life cycle of Monhystera parelegantula (Nematoda, Monhysteridae). Mar. Ecol. Prog. Ser. 6 : $67-72$

Vranken, G., Herman, P. M. J., Heip, C. (1988). Studies of the life history and energetics of marine and brackish-water nematodes I. Demography of Monhystera disjuncta at different temperature and feeding conditions. Oecologia 77: $296-301$

Wilkinson, L. (1990). SYSTAT: the system for statistics SYSTAT, Inc., Evanston, IL

Manuscript first received: January 30, 1992

Revised version accepted: November 24, 1992 